\title{
BATCH REPRESENTATION FOR A COATING IN ORDER TO EVALUATE THE "TCR" OF METAL FILM RESISTORS
}

\author{
A. P. GOSWAMI $\dagger$, M. Z. ATEEQ, L. SATYANARAYANA \\ Electronics Corporation of India Ltd. (E.C.I.L.), Resistors \& Capacitors Division, \\ Hyderabad-500 762, India \\ and \\ P. K. BASU \\ S.Q.C. Unit, Indian Statistical Institute, Hyderabad-500 483, India
}

(Received February 15, 1977, in final form November, 24, 1977)

\section{INTRODUCTION}

The general manufacturing technique for metal film resistors consists of several stages such as vacuum metallising, end capping, helixing, lead welding, ageing and final encapsulation. The two most important parameters in such resistors are the stability and temperature coefficient of resistance (TCR). It is now well known that whereas the former depends considerably on ageing conditions during the manufacturing process the latter changes only marginally during the whole process. Thus, the TCR of a metal film obtained after deposition and essential post evaporation treatments would remain nearly the same up to the finished stage. Consequently, a proper identification of TCR at the metallisation stage is of utmost importance to ensure a smooth and regular output with minimum rejections due to this parameter. In all metal film resistor manufacturing processes, TCR checking is carried out for 25,50 and $100 \mathrm{ppm} /{ }^{\circ} \mathrm{C}$ categories before final encapsulation to ensure that the product is as per the desired specification. It can be visualised that a considerable amount of production time is lost if $100 \%$ screening is done to sort out the TCRs either after deposition or at the finished stage. The pressure at these stages, as in any production line, could be greatly relieved if a random sampling of the TCRs was adopted. Such a technique would be feasible only if the sample taken to identify the TCR of the whole lot represents the lot characteristics.

†On leave to Dept. of Electronic \& Electrical Engineering, University of Technology, Loughborough, U.K.
Here, at the E.C.I.L., we use a $610 \mathrm{~mm}$ vacuum (24 in.) coating plant consisting of a rotary jig onto which special spools are loaded. These spools consist of needle shaped wires mounted on conical brass heads through which the ceramic tubes are inserted. (see Figure 1). The unique construction of such an arrangement is that as the jig rotates in vacuo a planetary motion as well as an axial rotation to the spools can be generated. The electron beam evaporation source is located below this jig and a resistance monitor above it for monitoring the desired ohmic ranges. This system consists of 120 spools and can coat 1500 to 2000 ceramic formers at a time depending on their size. The magnitude of the problem involved in measuring the TCR of all these pieces may be appreciated. Added to this is the sensitive variation of the TCR of chrome alloy films with thickness or sheet resistivity. ${ }^{1}$ This fact has also been corroborated by us during our earlier studies when all process conditions such as alloy composition, rate of evaporation, substrate temperature etc. were kept constant. From the design of the jig as shown in Figure 1, it can be seen that despite an optimum source substrate geometry there is likely to be a thickness gradient over the length of the spool thereby bringing in further complications. Unfortunately we have not been able to find a chrome alloy which has a uniform TCR over a wide range of sheet resistivities (film thickness) for resistors in the categories of 25,50 and $100 \mathrm{ppm} /{ }^{\circ} \mathrm{C}$. Although Campbell ${ }^{1}$ has suggested such a composition we however found it to be unsuitable in our evaporation system. Since measuring the TCR of 


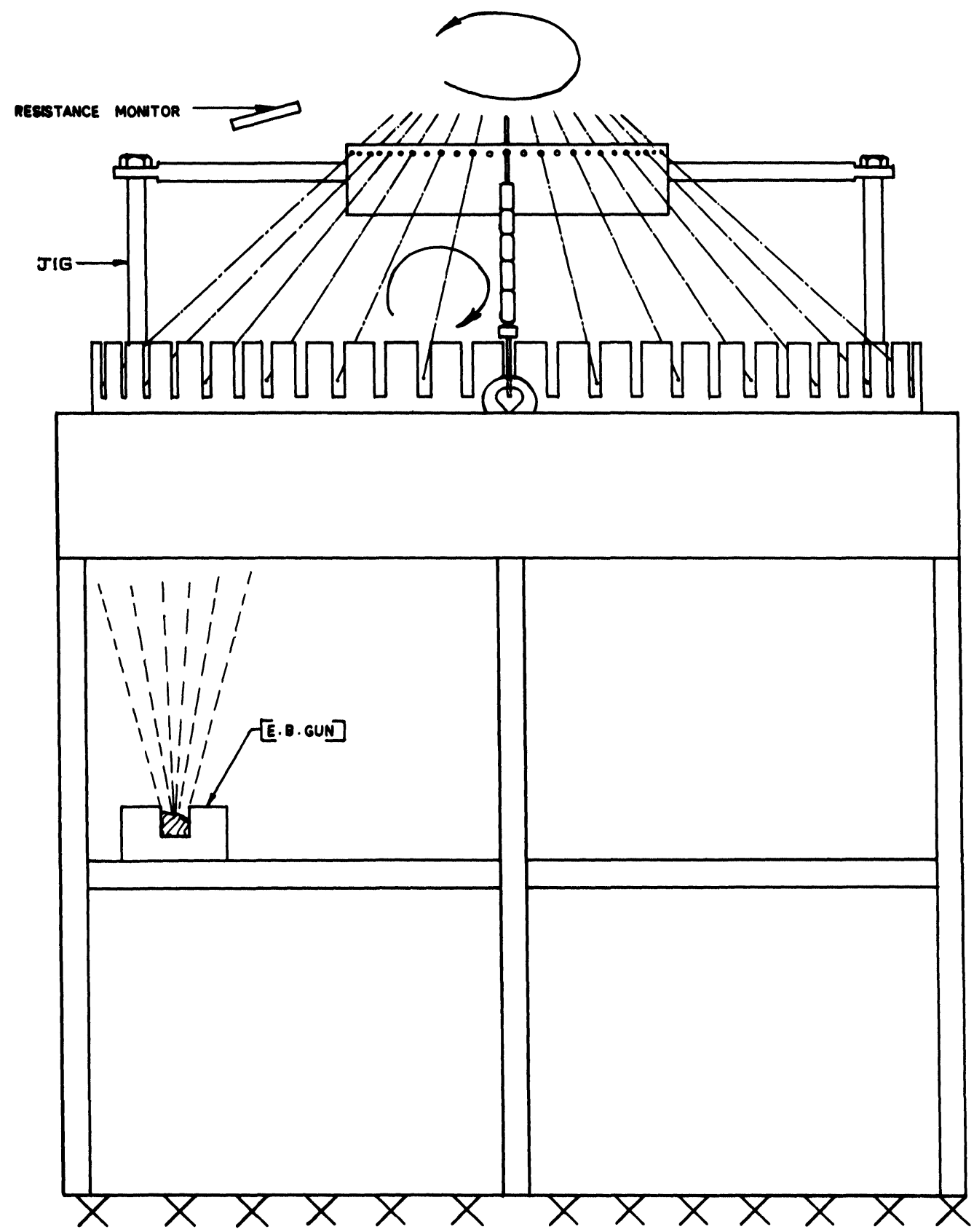

P Planar motion

Paxial MOtION

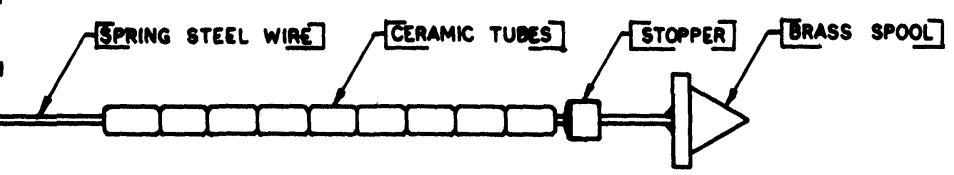

FIGURE 1 Construction of rotary jig and spools. 
TABLE I

Substrate resistances in ohms for five randomly selected spools

\begin{tabular}{|c|c|c|c|c|c|c|c|c|c|c|c|c|c|c|}
\hline \multirow[b]{2}{*}{$\begin{array}{l}\text { Spooi } \\
\text { No. }\end{array}$} & \multicolumn{14}{|c|}{ Position on spool } \\
\hline & 1 & 2 & 3 & 4 & 5 & 6 & 7 & 8 & 9 & 10 & 11 & 12 & 13 & 14 \\
\hline 1 & 26 & 20 & 21 & 18 & 18 & 18 & 22 & 24 & 24 & 23 & 22 & 25 & 30 & 40 \\
\hline 2 & 24 & 20 & 19 & 23 & 22 & 19 & 18 & 23 & 22 & 22 & 24 & 25 & 32 & 34 \\
\hline 3 & 22 & 19 & 20 & 23 & 18 & 24 & 23 & 20 & 20 & 24 & 20 & 28 & 32 & 38 \\
\hline 4 & 26 & 19 & 19 & 19 & 19 & 21 & 20 & 18 & 22 & 23 & 24 & 27 & 25 & 34 \\
\hline 5 & 23 & 18 & 20 & 20 & 22 & 22 & 21 & 22 & 24 & 25 & 20 & 28 & 32 & 38 \\
\hline
\end{tabular}

merely a handful of coated tubes would not give the true representation of a batch, a newer technique therefore has to be adopted for sampling. Since the TCR is related to the resistance value/sheet resistivity, a study of resistance variations would help to simplify the problem.

\section{DESIGN OF EXPERIMENT}

A closer look into the design features of the jig reveals the possible sources for resistance variations that may be obtained on the ceramic tubes in a batch. These can be broadly classified as -

1) variation of resistance of coated substrates between spools

2) variation of resistance of coated substrates within a single spool

3) any other unidentified sources that may arise due to uncontrollable factors (usually mentioned as chance causes).

Statistically these variations could be studied by using ANOVA (Analysis of variance) techniques and identifying the principal sources for variations. ${ }^{2,3}$ In this method the sum of squares of the different variations are computed and the degrees of freedom estimated. The mean sum of squares (m.s.s.) is then obtained to estimate the " $F$ " Ratio corresponding to certain confidence levels for that particular degree of freedom attributed to the source of variation. If this "F" ratio is less than the standard table value then, at that level of confidence, the variation due to the source is insignificant.

If the computed " $F$ " ratio is larger than the table value, the variation due to the source is significant. In the present study we have already outlined the factors that may contribute towards the resistance variations in a batch. Statistically all chance causes could be pooled and referred to as "error". 2,3 The assignable causes then become the sources for variation. For this study several production batches were selected at random and from each batch five random spools were chosen. After post evaporation treatments, caps were fitted on to the coated substrates and the resistance values measured to the nearest $\mathrm{ohm}$. Care was taken to see that the serial uniformity of the substrates on the spools was maintained. Each spool contained fourteen substrates. Table I shows typical data for one such production batch. The computation of sums of

TABLE II

Analysis of variance for data of Table I

\begin{tabular}{llllccc}
\hline $\begin{array}{l}\text { SL } \\
\text { No. }\end{array}$ & Source & $\begin{array}{l}\text { Sum of } \\
\text { squares } \\
\text { (SS) }\end{array}$ & $\begin{array}{l}\text { Degrees of } \\
\text { freedom } \\
\text { (df) }\end{array}$ & $\begin{array}{l}\text { Mean sum } \\
\text { of squares } \\
\text { (MSS) }\end{array}$ & $\begin{array}{l}\text { "F" ratio } \\
\text { calculated }\end{array}$ & $\begin{array}{l}\text { "F" table value } \\
\text { confidence } \\
\text { level 95\% }\end{array}$ \\
\hline 1 & Variation between spools & 16.92 & 4 & 4.23 & 1.04 & 2.53 \\
2 & Variation within spool & 1550.2 & 13 & 119.24 & $29.58^{\mathrm{a}}$ & 1.92 \\
3 & Error & 209.88 & 52 & 4.03 & - & - \\
4 & Total sum of squares & 1777 & 69 & - & - \\
\hline
\end{tabular}

\footnotetext{
${ }^{a}$ Significant.
} 
squares and the m.s.s. etc. are briefly outlined in Appendix A for the given data. ${ }^{2}$ The ANOVA thus obtained is given in Table II.

\section{INTERPRETATION}

It can be seen from Table II that with a confidence level of $95 \%$, variations within a spool in a single batch contribute significantly to the overall variations in the resistance values as compared with the other source. This no doubt is due to the source-substrate geometry which gives rise to a resistance gradient over the length of the spool. The study therefore establishes that since no significant variation in resistance values were obtained between the spools, a single spool containing the coated substrates would undoubtedly represent the lot characteristics of that batch. Similar results were also obtained with other production batches.

However, in view of the bulk production generated during manufacture it would be interesting to probe the usefulness of this analysis for a number of coated batches. If the process conditions were kept exactly identical and the resistance monitored for a fixed value then one would undoubtedly be led to speculate that a single spool from any one random batch would represent the lot characteristics of all the batches monitored to that value. Such a proposition would be of immense benefit in a large scale production. To study this phenomena we had selected, at random, five production batches prepared under identical process conditions. As seen earlier since a single spool could represent the lot characteristic of a batch we had for our purpose selected at random only two such spools from each of the five batches. Table III shows the data obtained.

\section{ANALYSIS AND INTERPRETATION}

As before the main sources for resistance variations could be attributed to the following factors viz -

1) variation of resistances between the batches

2) variation of resistances between spools in a batch

3) any other sources of variation due to uncontrollable factors and chance causes which can be pooled and called as error.

The relevant calculation for the mean sum of squares (m.s.s) for the above variations is shown in Appendix B. The ANOVA Table computed is given in Table IV.

The analysis of variance clearly reveals once again that there is no significant variation of resistance values within a batch even at a confidence level of $99 \%$. This corroborates our earlier findings establishing the fact that a single pool represented the lot characteristic of a batch. However, the variation due to the second source is significant even at $90 \%$ confidence level. Since there is no homogeneity in the characteristics of the five batches it would have been erroneous to represent it by the selection of a single spool from any one of these batches as speculated earlier. The non-homogeneity

TABLE III

Substrate resistances in ohms for two randomly selected spools per batch

\begin{tabular}{|c|c|c|c|c|c|c|c|c|c|c|c|c|c|c|c|c|}
\hline \multirow[b]{2}{*}{$\begin{array}{l}\text { Batch } \\
\text { No. }\end{array}$} & \multirow[b]{2}{*}{$\begin{array}{l}\text { Spool } \\
\text { No. }\end{array}$} & \multicolumn{15}{|c|}{ Position on the spool } \\
\hline & & 1 & 2 & 3 & 4 & 5 & 6 & 7 & 8 & 9 & 10 & 11 & 12 & 13 & 14 & Total \\
\hline A & $\begin{array}{l}1 \\
2\end{array}$ & $\begin{array}{l}26 \\
25\end{array}$ & $\begin{array}{l}18 \\
19\end{array}$ & $\begin{array}{l}19 \\
17\end{array}$ & $\begin{array}{l}18 \\
20\end{array}$ & $\begin{array}{l}20 \\
18\end{array}$ & $\begin{array}{l}16 \\
18\end{array}$ & $\begin{array}{l}19 \\
17\end{array}$ & $\begin{array}{l}18 \\
18\end{array}$ & $\begin{array}{l}17 \\
19\end{array}$ & $\begin{array}{l}16 \\
20\end{array}$ & $\begin{array}{l}17 \\
21\end{array}$ & $\begin{array}{l}17 \\
19\end{array}$ & $\begin{array}{l}20 \\
22\end{array}$ & $\begin{array}{l}22 \\
27\end{array}$ & $\begin{array}{l}263 \\
280\end{array}$ \\
\hline B & $\begin{array}{l}1 \\
2\end{array}$ & $\begin{array}{l}32 \\
32\end{array}$ & $\begin{array}{l}23 \\
22\end{array}$ & $\begin{array}{l}24 \\
26\end{array}$ & $\begin{array}{l}24 \\
28\end{array}$ & $\begin{array}{l}22 \\
27\end{array}$ & $\begin{array}{l}20 \\
24\end{array}$ & $\begin{array}{l}20 \\
21\end{array}$ & $\begin{array}{l}20 \\
20\end{array}$ & $\begin{array}{l}22 \\
22\end{array}$ & $\begin{array}{l}19 \\
24\end{array}$ & $\begin{array}{l}23 \\
23\end{array}$ & $\begin{array}{l}23 \\
27\end{array}$ & $\begin{array}{l}28 \\
32\end{array}$ & $\begin{array}{l}38 \\
38\end{array}$ & $\begin{array}{l}338 \\
366\end{array}$ \\
\hline $\mathrm{C}$ & $\begin{array}{l}1 \\
2\end{array}$ & $\begin{array}{l}24 \\
25\end{array}$ & $\begin{array}{l}23 \\
23\end{array}$ & $\begin{array}{l}21 \\
22\end{array}$ & $\begin{array}{l}19 \\
19\end{array}$ & $\begin{array}{l}23 \\
24\end{array}$ & $\begin{array}{l}21 \\
21\end{array}$ & $\begin{array}{l}18 \\
19\end{array}$ & $\begin{array}{l}21 \\
21\end{array}$ & $\begin{array}{l}20 \\
20\end{array}$ & $\begin{array}{l}20 \\
23\end{array}$ & $\begin{array}{l}18 \\
20\end{array}$ & $\begin{array}{l}18 \\
23\end{array}$ & $\begin{array}{l}28 \\
23\end{array}$ & $\begin{array}{l}28 \\
28\end{array}$ & $\begin{array}{l}302 \\
311\end{array}$ \\
\hline D & $\begin{array}{l}1 \\
2\end{array}$ & $\begin{array}{l}38 \\
27\end{array}$ & $\begin{array}{l}26 \\
23\end{array}$ & $\begin{array}{l}27 \\
25\end{array}$ & $\begin{array}{l}24 \\
23\end{array}$ & $\begin{array}{l}29 \\
28\end{array}$ & $\begin{array}{l}23 \\
26\end{array}$ & $\begin{array}{l}25 \\
22\end{array}$ & $\begin{array}{l}21 \\
22\end{array}$ & $\begin{array}{l}19 \\
23\end{array}$ & $\begin{array}{l}23 \\
20\end{array}$ & $\begin{array}{l}23 \\
25\end{array}$ & $\begin{array}{l}23 \\
23\end{array}$ & $\begin{array}{l}28 \\
27\end{array}$ & $\begin{array}{l}34 \\
28\end{array}$ & $\begin{array}{l}363 \\
342\end{array}$ \\
\hline$E$ & $\begin{array}{l}1 \\
2\end{array}$ & $\begin{array}{l}21 \\
15\end{array}$ & $\begin{array}{l}16 \\
15\end{array}$ & $\begin{array}{l}14 \\
18\end{array}$ & $\begin{array}{l}15 \\
18\end{array}$ & $\begin{array}{l}15 \\
19\end{array}$ & $\begin{array}{l}14 \\
13\end{array}$ & $\begin{array}{l}13 \\
14\end{array}$ & $\begin{array}{l}14 \\
15\end{array}$ & $\begin{array}{l}14 \\
14\end{array}$ & $\begin{array}{l}16 \\
15\end{array}$ & $\begin{array}{l}18 \\
17\end{array}$ & $\begin{array}{l}14 \\
20\end{array}$ & $\begin{array}{l}16 \\
20\end{array}$ & $\begin{array}{l}17 \\
21\end{array}$ & $\begin{array}{l}217 \\
234\end{array}$ \\
\hline
\end{tabular}


TABLE IV

Analysis of variance for data of Table III

\begin{tabular}{|c|c|c|c|c|c|c|c|}
\hline \multirow{2}{*}{$\begin{array}{l}\text { SL } \\
\text { No. }\end{array}$} & \multirow[b]{2}{*}{ Source of variation } & \multirow{2}{*}{$\begin{array}{l}\text { Sum of } \\
\text { squares } \\
\text { (SS) }\end{array}$} & \multirow{2}{*}{$\begin{array}{l}\text { Degree of } \\
\text { freedom } \\
\text { (df) }\end{array}$} & \multirow{2}{*}{$\begin{array}{l}\text { Mean sum } \\
\text { of squares } \\
\text { (MSS) }\end{array}$} & \multirow{2}{*}{$\begin{array}{l}\text { "F" ratio } \\
\text { calculated }\end{array}$} & \multicolumn{2}{|c|}{$\begin{array}{l}\text { "F" table value } \\
\text { confidence level }\end{array}$} \\
\hline & & & & & & $95 \%$ & $99 \%$ \\
\hline 1 & $\begin{array}{l}\text { Variation between spools } \\
\text { in a batch }\end{array}$ & 67.28 & 5 & 13.46 & 1.04 & 2.29 & 3.17 \\
\hline 2 & Variation between batches & 1693.18 & 4 & 423.30 & $32.66^{\mathrm{a}}$ & 2.45 & 3.48 \\
\hline 3 & Error & 1684.29 & 130 & 12.96 & - & - & - \\
\hline 4 & Total sum of squares & 3444.75 & 139 & - & - & - & - \\
\hline
\end{tabular}

${ }^{\mathrm{a}}$ Significant.

in the batches may be attributed to some uncontrollable factors present in our process. However the resistance monitor itself could have been a source of the discrepancy as its sensitivity reduces in the lower ohmic ranges (an Avometer was used for measuring the resistance on the monitor). Another source could be the rate of deposition. Since we could not use a crystal thickness monitor, preferential evaporation of the alloy could have taken place in spite of monitoring a constant rate as observed by the continuous change of resistance with time. ${ }^{4}$

\section{DISCUSSIONS}

The ANOVA technique applied has been able to identify that in the system used here and under the present working conditions, coated substrates from a single spool in a batch would be sufficient to represent the lot characteristic of the batch. This representation has another advantage that any resistance (sheet resistivity) gradient present in the system due to source-substrate geometry would be taken care of adequately.

The second analysis reveals that since there is no homogeneity of resistance values between batches, even though the process conditions were kept identical, separate sampling for the batches become an essential feature. However a single spool from each batch could be selected as representative. These results are statistically valid with a confidence level of $99 \%$.

Having thus obtained the representative sample size of a coated batch, TCR measurements were carried out and batch characteristics identified before the coated substrates were sent for actual production. Some allowance for drift, though marginal, in TCR due to the manufacturing process should be given. For the sake of bulk production coated batches of the same TCR catagories were then generally mixed and identified as a lot having homogeneous properties. Coated substrates drawn from such lots for processing into finished resistors must therefore reflect the properties of the lot. Before final encapsulation a routine check of TCR of the resistors is carried out to ascertain whether they are in the desired category $\left(25,50\right.$ or $\left.100 \mathrm{ppm} /{ }^{\circ} \mathrm{C}\right)$. Hitherto this was a major bottleneck in the process as 100\% measurements for TCR of the resistors had to be done. Because of the homogeneity in a lot the TCR of the semi-finished resistors drawn from such a lot could be evaluated simply by random sampling. Standard sampling plans are available in reputed statistical handbooks and we have selected one such plan $^{5}$ which had an AOQL (Average Outgoing Quality Limit) at $4 \%$. As a result of this sampling technique an almost ninefold increase in production was achieved at this stage with minimum rejections (less than 7\%). Resistors which passed at this stage by sampling rarely failed when final inspections were made by the quality assurance section. Rejections that did occur were generally attributed to the following reasons.

1) erroneous TCR measurements after deposition

2) TCR batch identification being lost during the production sequences.

In a majority of the cases, the latter was found to be an important factor as we handle on an average each month more than 200,000 resistors in four wattages, TCRs and more than one hundred standard values. These are being reduced by implementing proper check points at strategic production stages. 


\section{ACKNOWLEDGEMENT}

We are extremely grateful to Prof. D. S. Campbell of Loughborough University of Technology for his encouragement and valuable suggestions for this work.

\section{REFERENCES}

1. D. S. Campbell and B. Henry, Brit. J. Appl. Phys., 16, 1719 (1965).
2. J. M. Juran, Quality Control Handbook, 3rd Ed., (McGraw-Hill Co Ltd.) Section 27.

3. K. A. Brownlee, Statistical Theory and Methodology in Science and Technology, 2nd Ed., (John Wiley \& Sons Inc.)

4. M. Z. Ateeq, Diploma dissertation submitted to Government Polytechnic, Hyderabad, (1975).

5. H. F. Dodge and H. G. Roming, Sampling Inspection Tables, 2nd Ed., (John Wiley \& Sons Inc.), 217.

\section{Appendix A}

Method of computation

1) Sum of all the observations

2) Total No. of observations

3) Correction Factor (CF)

4) Total sum of squares

5) Sum of squares between spools (SSS)

6) SS between pieces (SSW) in a spool

7) Total degrees of freedom (df)

8) "df" due to spool

9) "df" between pieces in a spool

10) Error sum of squares

11) “df" for error

12) Mean sum of squares (m.s.s.)

13) "F" Ratio for source
Results

$26+20 \ldots \ldots \ldots$ ..... $32+38$

70

$(1)^{2} /(2)$

38,376

Sum of squares of all the observations 1,777 minus correction factor

Sum of each row, squares, sum of all such squares, divided by No. of observations minus correction factor (CF)

Same as above for columns

Total No. of observations minus one

(4) $-(5)-(6)$ 209.88

(7)-(8)-(9)

Sum of squares/df

m.s.s. of source

m.s.s. of error 


\section{Appendix B}

Method of Computation

Results

1) Sum of all the observations

$26+18+19 \ldots \ldots$

3,016

$\ldots \ldots \ldots 20+20+21$

140

2) Total No. of observations

$64,973.25$

3) Correction Factor (CF)

$(1)^{2} /(2)$

$3,444.75$

4) Total sum of squares

$26^{2}+18^{2}+\ldots .20^{2}+21^{2}-\mathrm{CF}$

5) Sum of squares between spools within a batch

$\frac{\left(263^{2}+280^{2}+\ldots 234^{2}\right)}{14}-$

67.28

$\frac{(263+280)^{2}+\ldots \ldots(217+234)^{2}}{28}$

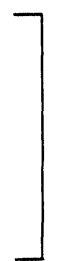

6) Sum of squares between batches

$\left[\frac{(263+280)^{2}+\ldots \ldots+(217+234)^{2}}{28}\right]-\mathrm{CF}$

7) Total degrees of Freedom (df)

Total No. of observations minus one

8) Degrees of freedom for spools within batches

9) Degrees of freedom for batches

10) Error sum of squares

(4) $-(5)-(6)$

4

(7)-(8)-(9)

$1,684.29$

11) Degrees of freedom for error (SS)

12) Mean sum of squares

Sum of squares/df

13) "F" Ratio for source

m.s.s. for source

m.s.s. for error 

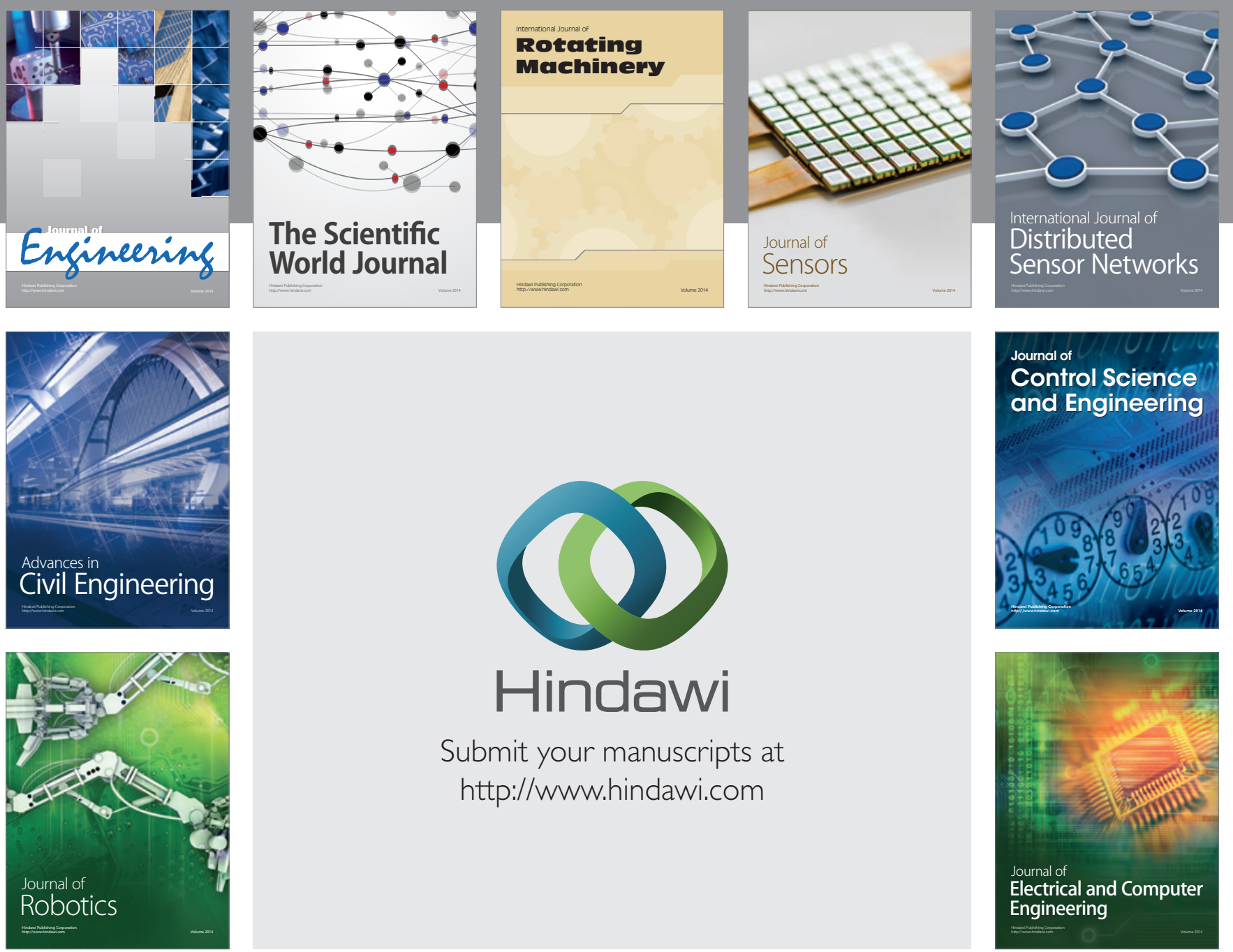

Submit your manuscripts at

http://www.hindawi.com
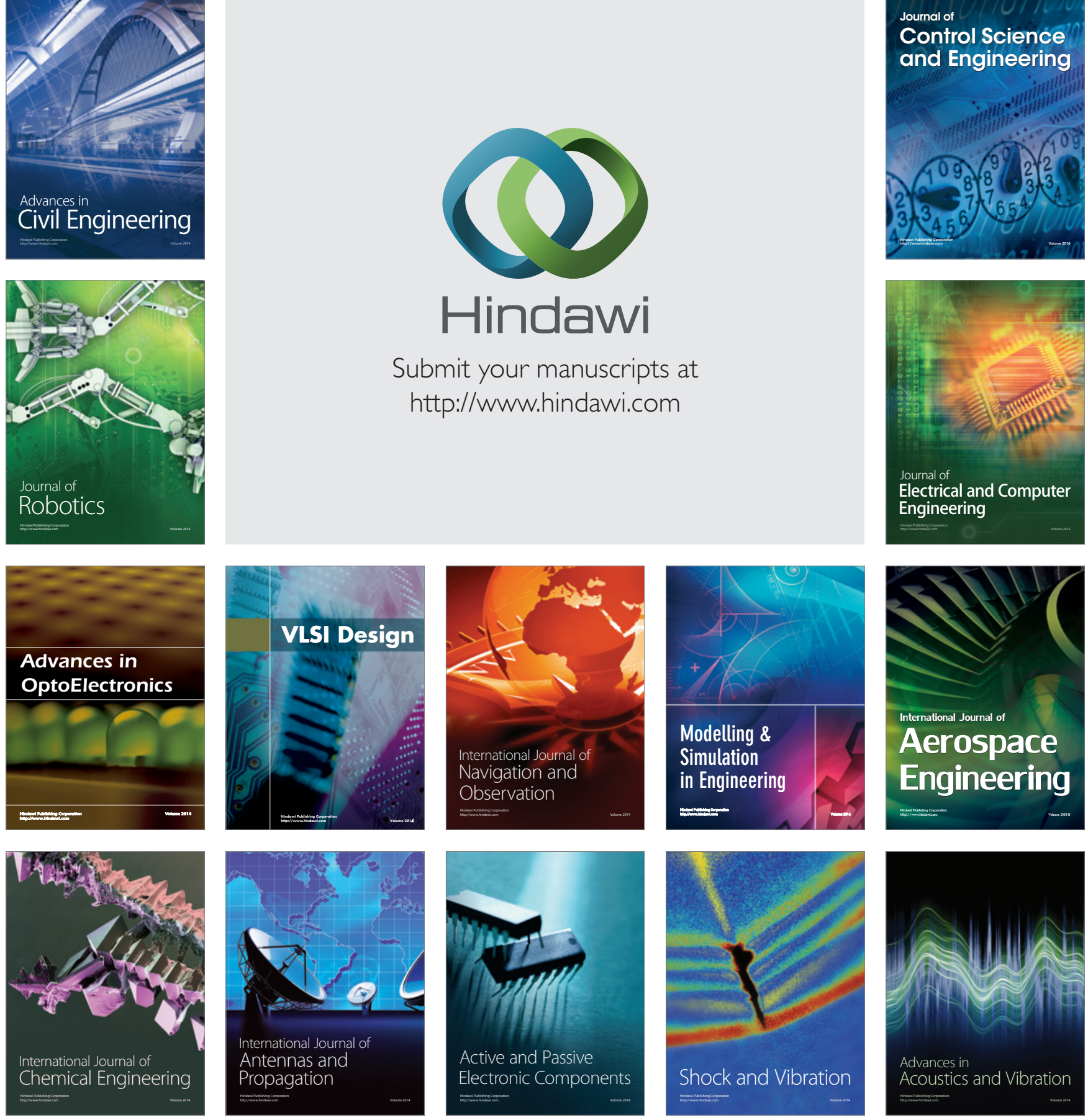